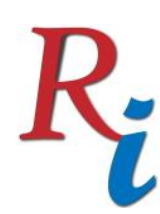
$\Gamma \Gamma$
$S C \mid E N C E$ P ROCEED IN
GS SER I E S
http://readersinsight.net/SPS

\title{
CyBer SeCuRIty AWARENESS AMONG UNIVERSITy STUDENTS: A CASE STUDY
}

\author{
Adamu Abdullahi Gabra* \\ Faculty of Engineering, School of Computing \\ Universiti Teknologi Malaysia \\ Malaysia \\ admugaidam@gmail.com \\ Maheyzah Binti Sirat \\ Faculty of Engineering, School of Computing \\ Universiti Teknologi Malaysia \\ Malaysia \\ maheyzah@utm.my \\ Siti Hajar \\ Faculty of Engineering, School of Computing \\ Universiti Teknologi Malaysia \\ Malaysia \\ hajar@utm.my

\section{Ibrahim Bukar Dauda} \\ Azman Hashim International Business School \\ Universiti Teknologi Malaysia \\ Malaysia \\ ibrahimbukardauda88@gmail.com
}

*Corrosponding author's Email: adamugaidam@gmail.com

Peer-review under responsibility of 4th Asia International Multidisciplinary Conference 2020 Scientific Committee

http://connectingasia.org/scientific-committee/

(C) 2020 Published by Readers Insight Publisher,

lat 306 Savoy Residencia, Block 3 F11/1,44000 Islamabad. Pakistan,

editor@ readersinsight.net

This is an open access article under the CC BY-NC-ND license (http://creativecommons.org/licenses/by-nc-nd/4.0/). 

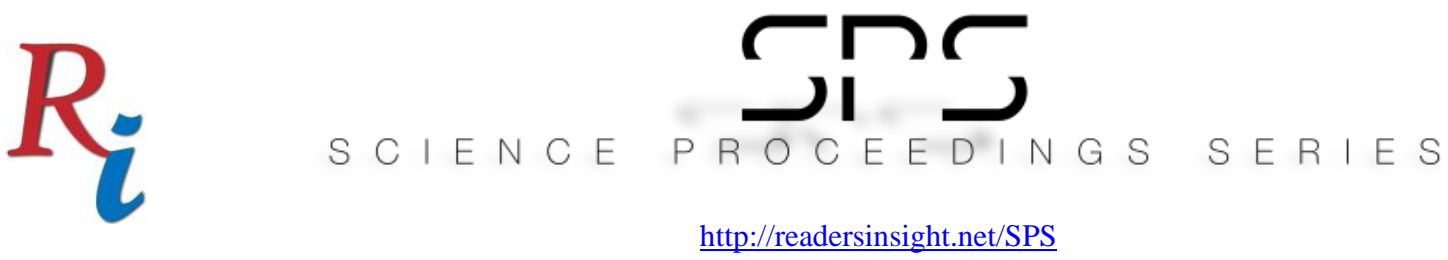

\section{A b s t r a c t}

This Case Study reports the preliminary results of a quantitative survey aimed to identify students' awareness and enthusiasm to learn cybersecurity in Nigerian Universities. The objective of the survey was to see how students in this developing country are aware of cyberattacks and how they can mitigate the attacks and to find out if cybersecurity awareness program is part of the University program. The preliminary results indicated that the students claimed to have basic cybersecurity knowledge, but are not aware of how to protect their data. It also appears that most Universities do not have an active cybersecurity awareness program to improve students' knowledge on how to protect themselves from any threats. The surveyed students also show interest in learning more about cybersecurity.

\section{Rese a r ch H i g h I igh t s}

The result of the research has indicated there is not any approach in place to increase the level of cybersecurity awareness to students at universities in Nigeria, the results also show that students lack the basic knowledge of cybersecurity. This research highlighted the urgent need to conduct a cybersecurity awareness program and to also include it as a core course at the university level in Nigeria. Similar research was conducted in different countries to see the level of cybersecurity, (1) in Malaysia, Also in India (2),(3) in California, (4) in the US, all results indicated lack of proper cybersecurity awareness and a need of awareness program is needed to increase the level of awareness and minimize successful cyber- attacks.

\section{Research Objectives}

The research objectives are to identify the level of basic knowledge of cybersecurity among university students in Nigeria, To identify if cybersecurity is among their curriculum or a seminar class and also to identify if the cybersecurity awareness program is needed or not, to understand if cybersecurity awareness program is required. This quantitative research will be significant to other researchers as a baseline for carrying other research, e.g. going straight on conducting the cybersecurity awareness program among university students in Nigeria without any assessment.

\section{Methodology}

This research uses a quantitative approach in designing the questionnaire-based survey to collect data using an online method. The questions were organized to obtain the level of cybersecurity awareness level among the targeted participant. The participant is university 

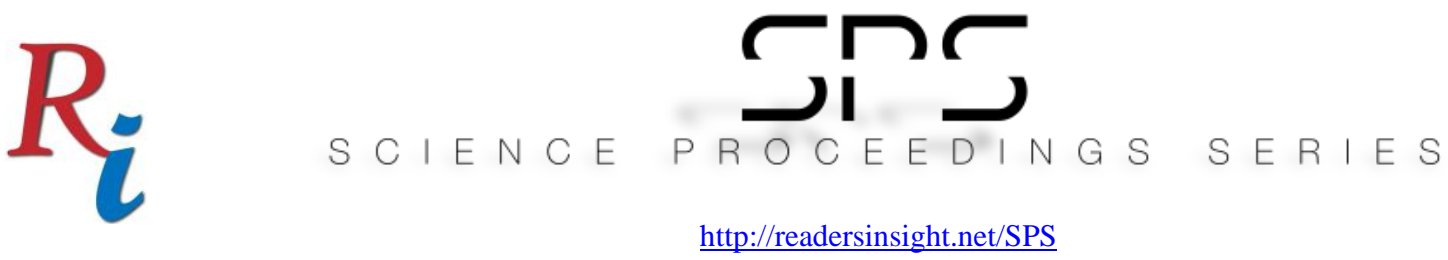

students in Nigeria. This group was selected as a result of using the information as part of their daily activities and also students are the future employees in any organization. The survey link was distributed among students in Nigerian universities from January 2020 to the end of February the same year. Based on the above objectives the questions were drafted and an online platform was used as a medium where the student can access and fill the questionnaire. The questionnaire consists of 19 main questions and their answers were limited to "Yes", "No" and "Maybe" with five demography questions. The estimated time for a participant to complete the survey is around 15 to 20 minutes. The questions were designed to provide answers to the objective of the paper, the key focus area includes Basic knowledge of cybersecurity Trust, Privacy, Password management, the desire to learn cybersecurity and cybersecurity awareness program as a course the question was adopted form $(5,6)$

\section{Results}

The results of the survey indicate that university students lack the basic knowledge of cybersecurity, even when the results on the questions shows that students have basic knowledge around 193 said yes and 82 said No and other are not sure answered maybe which is 90, but the subsequent questions indicated the lack of cybersecurity awareness. Among the question is that of password management result analysis which shows 204 said No, 139 said yes and 22 said maybe to using hard to guess password also, the question on opening an email sent from an unfamiliar person, the result shows, a total of 219 said yes out of 367, 110 said no and 36 said maybe. This result indicates the majority of students lack the knowledge of phishing attacks. The results appear to show that all the institutions lack cybersecurity programs and no indication of the cybersecurity program and a total of 346 respondents out 367 strongly desire to learn more about cybersecurity. Finally, this results obtained from this survey it indications, cybersecurity awareness program is not conducted in Nigerian tertiary institutions, it also indicates lack of basic cybersecurity knowledge, the survey also indicates students are demanding such cybersecurity awareness.

\section{Findings}

The research findings include: the cybersecurity awareness program is not conducted in Nigerian tertiary institutions, it also indicates a lack of basic cybersecurity knowledge among university students such as password Management. The finding also shows the desire to learn more about cybersecurity by the students, it also shows students are at high risk of cyber-related attacks. 


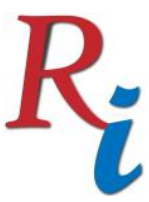

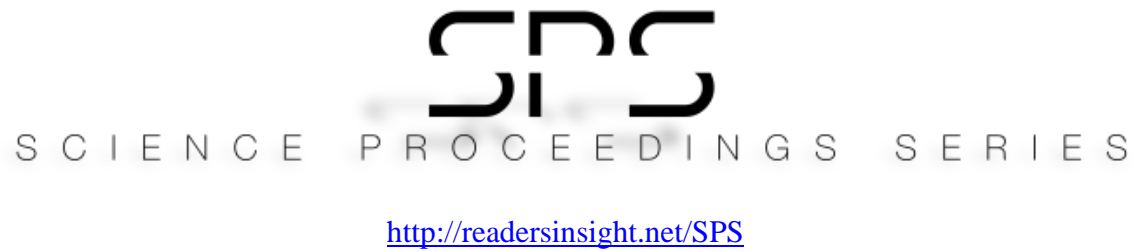

http://readersinsight.net/SPS

\section{REFERENCES}

[1] Kirwan GH, Fullwood C, Rooney B. Risk Factors for Social Networking Site Scam Victimization Among Malaysian Students. 2017;00(00):1-6.

[2] Yang Y, Zhou L, Peng Z, Using S, Spread N, Deng S, et al. A Survey on Cyber Security awareness among college students in Tamil Nadu A Survey on Cyber Security awareness among college students in Tamil Nadu. 2017;

[3] Slusky L, Partow-Navid P. Students Information Security Practices and Awareness. J Inf Priv Secur. 2012;8(4):3-26.

[4] Cone BD, Irvine CE, Thompson MF, Nguyen TD. A video game for cyber security training and awareness. Comput Secur. 2007;26(1):63-72.

[5] Moallem A. Cybersecurity Awareness Among Students and Faculty [Internet]. Vol. 2, Cybersecurity Awareness Among Students and Faculty. Springer International Publishing; 2019. 79-87 p. Available from: http://dx.doi.org/10.1007/978-3-319-947822_8

[6] Al-Janabi S, Al-Shourbaji I. A Study of Cyber Security Awareness in Educational Environment in the Middle East. J Inf Knowl Manag. 2016;15(1).

Author's Biography

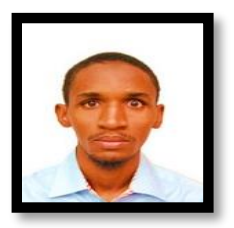

Adamu Abdullahi Garba is a Ph.D. Student at Universiti Teknologi Malaysia, and an Assistant lecturer at Yobe State University Damaturu Nigeria on leave of study, he got his first degree at the University of East London in Software Engineering in 2013 and Master in Computer Science at Universiti Teknologi Malaysia in 2015. His current research interest is information security, cybersecurity, and database management and software engineering. He is a member of Information Assurance and Security Research Group (IASRG), Department of Computing Faculty of Engineering Univerisiti Teknology Malaysia (UTM)

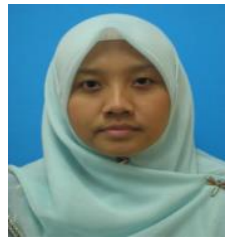

Dr. Maheyzah Binti Sirat received the B.Eng. degree in Computer Engineering from Universiti Teknologi Malaysia (UTM), Malaysia in 2000 and the MEngSc degree in Computer and communication engineering from Queensland University of Technology (QUT), Australia, in 2003 and Ph.D. in Computer Science from Universiti Teknologi Malaysia (UTM), Malaysia in 2012. She is an active member of Information Assurance and Security Research Group (IASRG), IEEE and IACSIT. Currently, she is the Coordinator for M.Sc. of Information Security program. Her major research interests revolve around Information Security and Assurance including Intrusion Detection, Alert Correlation, and Analysis, Intrusion Response and Prevention, Network/Digital Forensic 

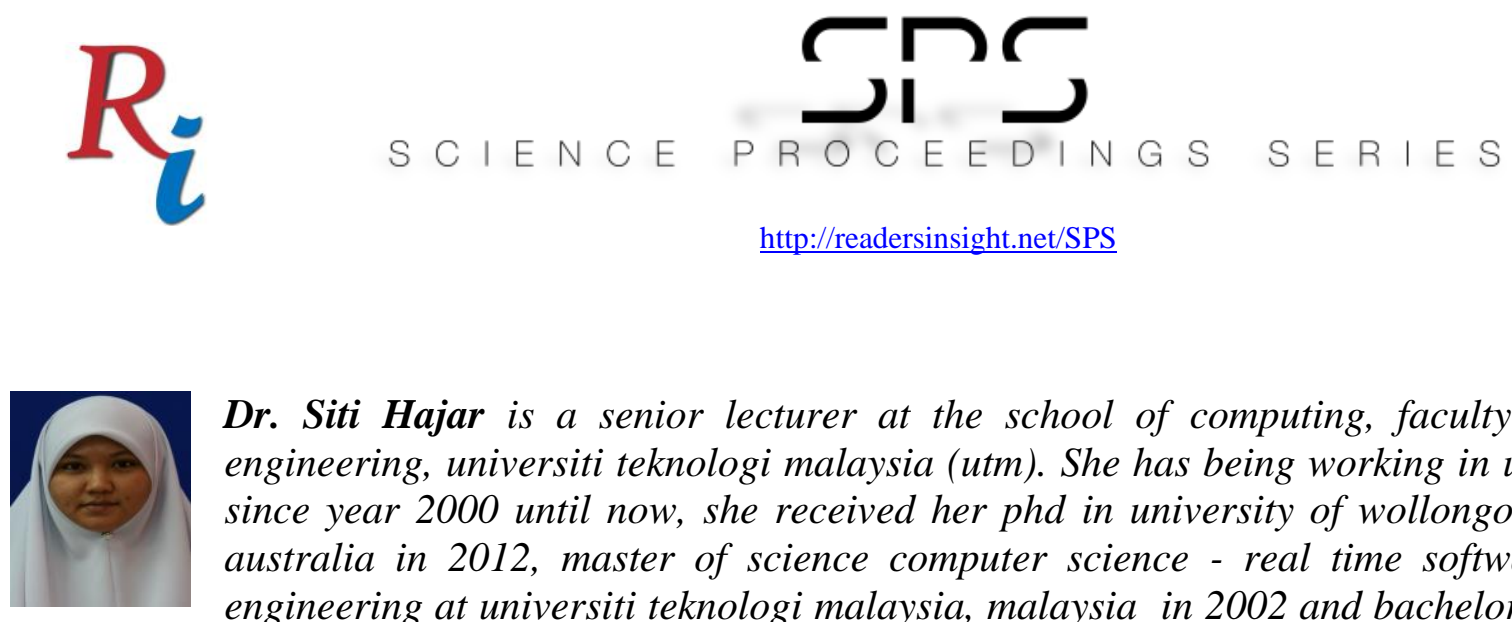

Dr. Siti Hajar is a senior lecturer at the school of computing, faculty of engineering, universiti teknologi malaysia (utm). She has being working in utm since year 2000 until now, she received her phd in university of wollongong, australia in 2012, master of science computer science - real time software engineering at universiti teknologi malaysia, malaysia in 2002 and bachelor of science computer science - majoring in computer system at universiti teknologi malaysia, malaysia in 2000. Her research interests are in Security Management - IT Security Audit, IT Disaster Recovery, Information Security, Cryptocurrency, Cybersecurity, Disaster Management, Computer Forensic, Knowledge Retrieval, Conceptual Modelling.

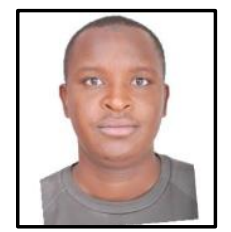

Ibrahim Bukar dauda received his Bsc in Limkokwing University malaysia, in Business information Technology in 2012, and masters in Management of information Technology at Coventry university, United kingdom in 2015 he an Assistant lecturer at Yobe State University Damaturu Nigeria on study leave, he is currently a PhD student at Azman Hashim International Business School, Universiti Teknologi Malaysia, Malaysia. His Research interest include Health information systems, knowledge Management. 